\title{
Surface Heat Flux Measurement in Transpiration Cooled Porous Materials using Plenum Pressure Data
}

\author{
Fabian Hufgard*, Stefan Loehle ${ }^{\dagger}$, Jens von Wolfersdorf ${ }^{\ddagger}$, Stefanos Fasoulas ${ }^{\S}$, \\ University of Stuttgart, 70569 Stuttgart, Germany \\ Marc Ewenz Rocher"I, Tobias Hermann", Matthew McGilvray** and \\ The University of Oxford, Oxford OX2 OES, United Kingdom \\ Johan Steelant ${ }^{\dagger \dagger}$ \\ ESTEC-ESA, 2200 AG Noordwijk, The Netherlands
}

\begin{abstract}
It was demonstrated recently, that in transpiration cooled environments, the plenum pressure is sensitive to the surface heat flux. The Pressure Based Non-Integer System Identification (NISIp) method was found to be useful for the identification of pressure impulse responses of such systems. Using an identified system, an unknown surface heat flux can be reconstructed by measurement of the plenum pressure and deconvolution with the found pressure impulse response. Since a heat flux measurement at transpiration cooled surfaces is of fundamental interest in many applications of high-speed vehicles and propulsion systems, this methodology is intended to be further developed towards a heat flux sensor. A review of the methodology, the experimental setup and the results of first heat flux measurements in the plasma wind tunnel PWK4 at the Institute of Space Systems, Stuttgart are presented in this paper. Surface heat flux profiles for different coolant mass flow rates have been successfully determined using plenum pressure data.
\end{abstract}

\section{Nomenclature}

$D=$ (non-integer) derivation

$\dot{m}=$ mass flow rate

$p_{p l}=$ plenum pressure

$q_{0}=$ surface heat flux

$I R=$ impulse response

$t=$ time

$\alpha_{n}=$ NISI-coefficients for pressure

$\beta_{n}=$ NISI-coefficients for heat flux

\section{Introduction}

In aerospace engineering applications, components can be subject to extreme surface heat fluxes. Examples of this are heat shields for reentry vehicles or the internal wall structures of combustion chambers for rockets or (sc)ramjets [1-3]. In order to maintain structural integrity, active cooling is necessary for some applications. One such technology that has become more popular in the last decades is transpiration cooling. Here, a gaseous or liquid coolant is fed through

*PhD student, High Enthalpy Flow Diagnostics Group, Institute of Space Systems, Pfaffenwaldring 29.

${ }^{\dagger}$ Research scientist, Head of High Enthalpy Flow Diagnostics Group, Institute of Space Systems, Pfaffenwaldring 29, AIAA Member.

† Professor, Institute of Aerospace Thermodynamics, Pfaffenwaldring 31, AIAA Member.

$\S$ Professor, Head of the Institute of Space Systems, Pfaffenwaldring 29, AIAA Member.

IIPhD student, Hypersonics Group, Osney Thermofluids Institute, Osney Mead, The Southwell Building.

" Post-doctoral research assistant, Hypersonics Group, Osney Thermofluids Institute, Osney Mead, The Southwell Building, Osney Mead, The Southwell Building, AIAA Member.

**Associate Professor, Hypersonics Group, Osney Thermofluids Institute, Osney Mead, The Southwell Building.

${ }^{\dagger}$ Professor and senior research scientist, Flight Vehicles and Aerothermodynamics Engineering Section, Keplerlaan 1, P.O. Box 299. 
the wall, which consists of a porous material, into the hot gas region. This has two effects. Firstly, the wall is actively cooled by the coolant, where the thermal energy is fed back into the hot gas region. Secondly, the coolant acts like an additional heat shield by forming a layer of comparatively cold gas between wall and hot gas. The second effect is not an actual cooling effect in the literal sense, but rather a reduction of the surface heat flux. A detailed description of this process can be found in Böhrk et al. and references therein [4].

Significant improvement in the design of transpiration cooled applications requires a thorough characterization of the transpiration cooling by distinct measurements of temperatures and pressures. One essential parameter is the surface heat flux to which the material is exposed. Measurement of surface heat flux is still a challenging endeavour. One method, which has been developed by the High Enthalpy Flow Diagnostics Group (HEFDiG) at the Institute of Space Systems of the University of Stuttgart is the Non-Integer System Identification (NISI). Here, the basic idea is to characterize the respective sensor system entirely by using non-destructive testing of the actual hardware. A single calibrated temperature sensor suffices for the inverse determination of surface heat flux without a detailed knowledge of thermophysical properties and geometry of the sensor [5, 6]. It was shown in previous publications that for transpiration cooled systems subject to a constant coolant mass flow, the plenum pressure change is sensitive to the surface heat flux. Therefore, the NISI method can be used for the identification of a pressure impulse response from the measured plenum pressure profile [7, 8]. The NISI method's pressure-based alteration NISIp appears to be a promising foundation to the development of a novel heat flux sensor.

The first successful application of the NISIp method in a relevant test facility was achieved by Schweikert et al. in the hot gas test facility at the Institute of Aerospace Thermodynamics (ITLR) of the University of Stuttgart [9]. Using a NISIp calibrated porous carbon/carbon sample a maximum heat flux of approximately $23 \mathrm{~kW} / \mathrm{m}^{2}$ was measured. The next step in the development of the NISIp method is the demonstration of its applicability at even higher heat fluxes. The arc jet plume in the plasma wind tunnel (PWK4) at the Institute of Space Systems (IRS) of the University of Stuttgart impose surface heat fluxes in the order of $\mathrm{MW} / \mathrm{m}^{2}$. The results of NISIp heat flux measurements in this facility using a sensor head with a porous $\mathrm{ZrB}_{2}$ sample are presented in this paper.

\section{Methodology}

The composite nature of the NISIp approach is summarized in Fig. 1. The underlying NISIp equation given by

$$
\sum_{n=M_{0}}^{M} \alpha_{n} D^{n / 2} p_{p l}(t)=\sum_{n=L_{0}}^{L} \beta_{n} D^{n / 2} q_{0}(t) \quad \text { with } \quad \alpha_{M_{0}}=1
$$

correlates the plenum pressure to the surface heat flux [7, 8]. The equation originally formulated with $T(t)$ instead of $p_{p l}(t)$ was derived for different heat conduction problems using analytical approaches [5, 10, 11]. In this study, it is used with the plenum pressure. However, a mathematical analysis of the applicability is still pending. During calibration, a well known heat flux is applied to the surface using a calibration laser. The plenum pressure is measured using a commercial gauge. With a known heat flux and pressure profile, the only unknowns in Eq. (1) are the parameters $\alpha_{n}$ and $\beta_{n}$. These are identified in the first step of the NISIp approach by rebuilding the pressure signal and fitting it with a least-squares approach to the measured pressure profile. In the second step of a NISIp calibration, the identified set of parameters is used to calculate the pressure profile for a numerical Dirac impulse. The resulting pressure profile

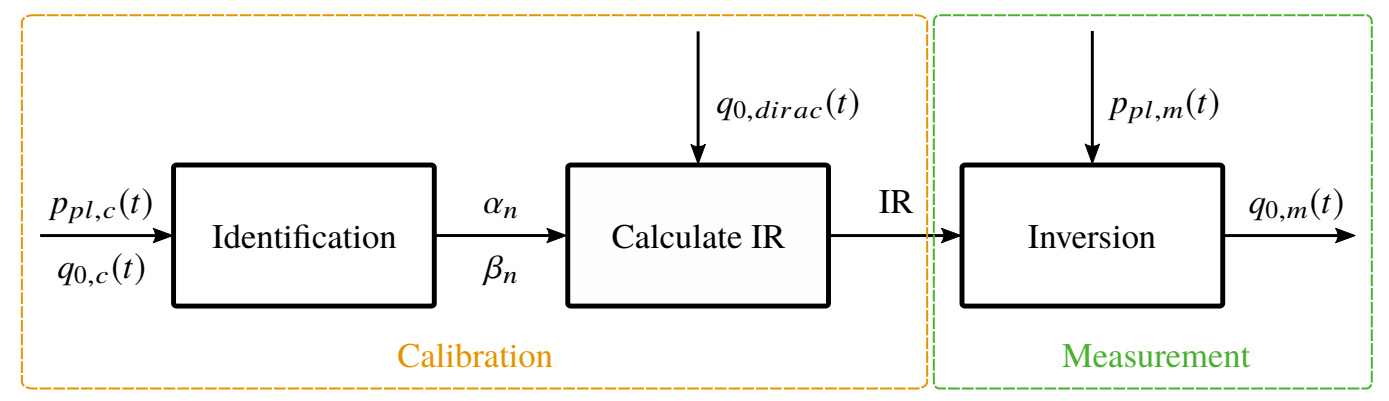

Fig. 1 Schematic of the composite nature of the NISIp approach consisting of calibration and measurement; $\mathrm{IR}=$ impulse response, $\mathrm{o}=$ surface, $\mathrm{pl}=$ plenum, $\mathrm{m}=$ measurement, $\mathrm{c}=$ calibration . 
represents the system's impulse response, which fully characterizes this particular system and therefore provides its temporal behaviour [12]. In the last step of the procedure, the measurement case, the found pressure impulse response is used to determine the surface heat flux by deconvolution with the measured pressure profile. In the present investigation, a Phased Van-Cittert algorithm was applied [13].

\section{Experimental Hardware}

\section{A. Calibration Setup}

As described in section III], a given sensor system needs to be calibrated prior to heat flux measurements in order to apply the NISIp method. Fig. 2 shows the NISIp calibration setup. Essentially, it consists of a laser system, a flow controller, the probe containing the transpiration-cooled porous sample and the pressure gauge. For the application of a calibrated sensor system to a measurement scenario, the respective probe setup needs to be identical including the pressure sensor, the flow controller and all parts forming the plenum (e.g. tubes). This was taken into account when the calibration setup was designed.

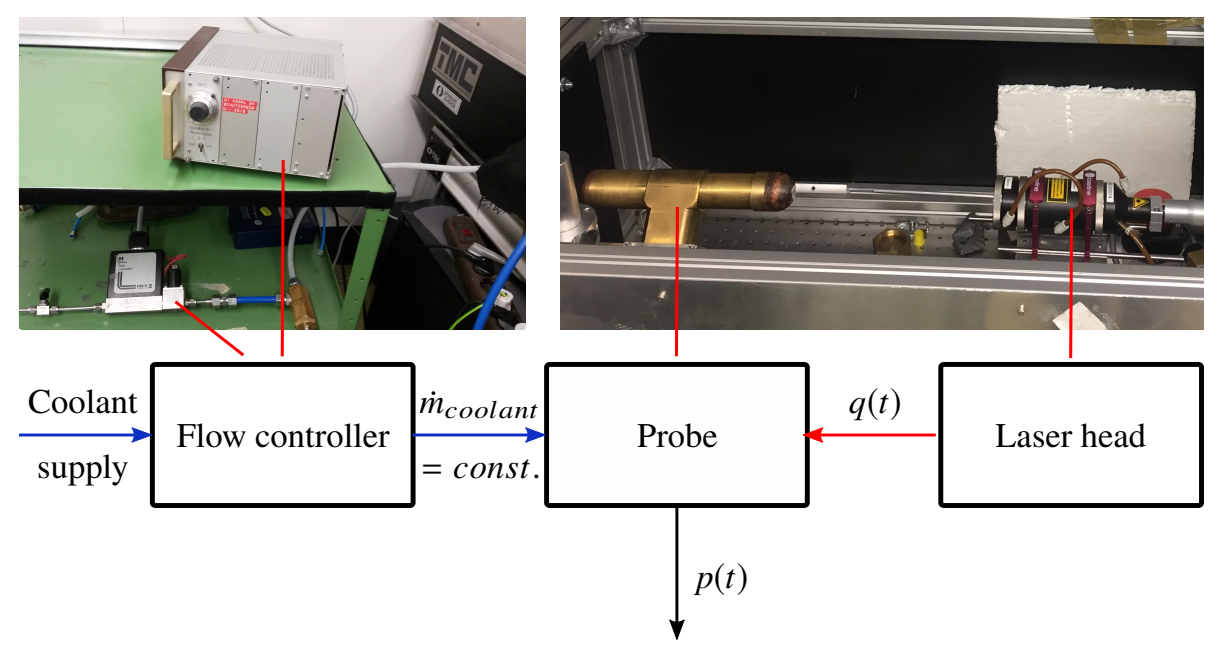

Fig. 2 Schematic of the laser calibration setup for NISIp applications.

A diode laser (Laserline LDM 500-100) with a wavelength of $980 \mathrm{~nm}$ and a power rise time of $<0.1 \mathrm{~ms}$ was used. The laser power is determined with the manufacturer's calibration information from the power setting. The focusing optics distributes the laser beam homogeneously into a round laser spot with a radius of $11.1 \mathrm{~mm}$. A maximum optical output power of $540 \mathrm{~W}$ is achievable. A constant coolant mass flow is provided by a flow controller, as this is required by the NISIp method. Nitrogen and Helium were used as coolants, were the respective sensor head was calibrated with the same gas, which was later used in the plasma wind tunnel tests. The flow controller used was an in-house system at IRS. It's actuator was a Tylan 2900 series 10 SLPM CO. The plenum pressure was recorded by an Omega PXM-319 absolute 0-15 bar pressure gauge. The plenum pressure and the laser demand, which can be recalculated to the optical laser power, were acquired using an oscilloscope LeCroy WaveSurver $24 \mathrm{Xs}$-A.

The measurement campaign this probe was used for was conducted within the framework of a cooperation between HEFDiG and Oxford Thermofluids Laboratory. The probe design arouse from joint efforts. Fig. 3 gives insight into the composition of the probe. The porous $\mathrm{ZrB}_{2}$ sample is glued into a $\mathrm{ZrO}_{2}$ insulation ring and integrated into the hemispherical copper probe head. This side of the probe is facing the plasma flow during testing in the plasma wind tunnel and the laser head during calibration. The coolant is injected into the probe through a tube, which is connected to the bottom of the probe stand. The probe stand and the probe core was manufactured at IRS. The sensor head (and its adapter) were built and assembled by the Oxford Thermofluids Laboratory. The porous $\mathrm{ZrB}_{2}$ sample therein was manufactured and characterized by the Department of Materials of Imperial College London. The data acquired by the depicted pyrometer were used by the Oxford Thermofluids Laboratory [14]. As this instrument was present during the tests in the plasma wind tunnels, it needed to be placed inside the plenum in order to assure a valid calibration. 


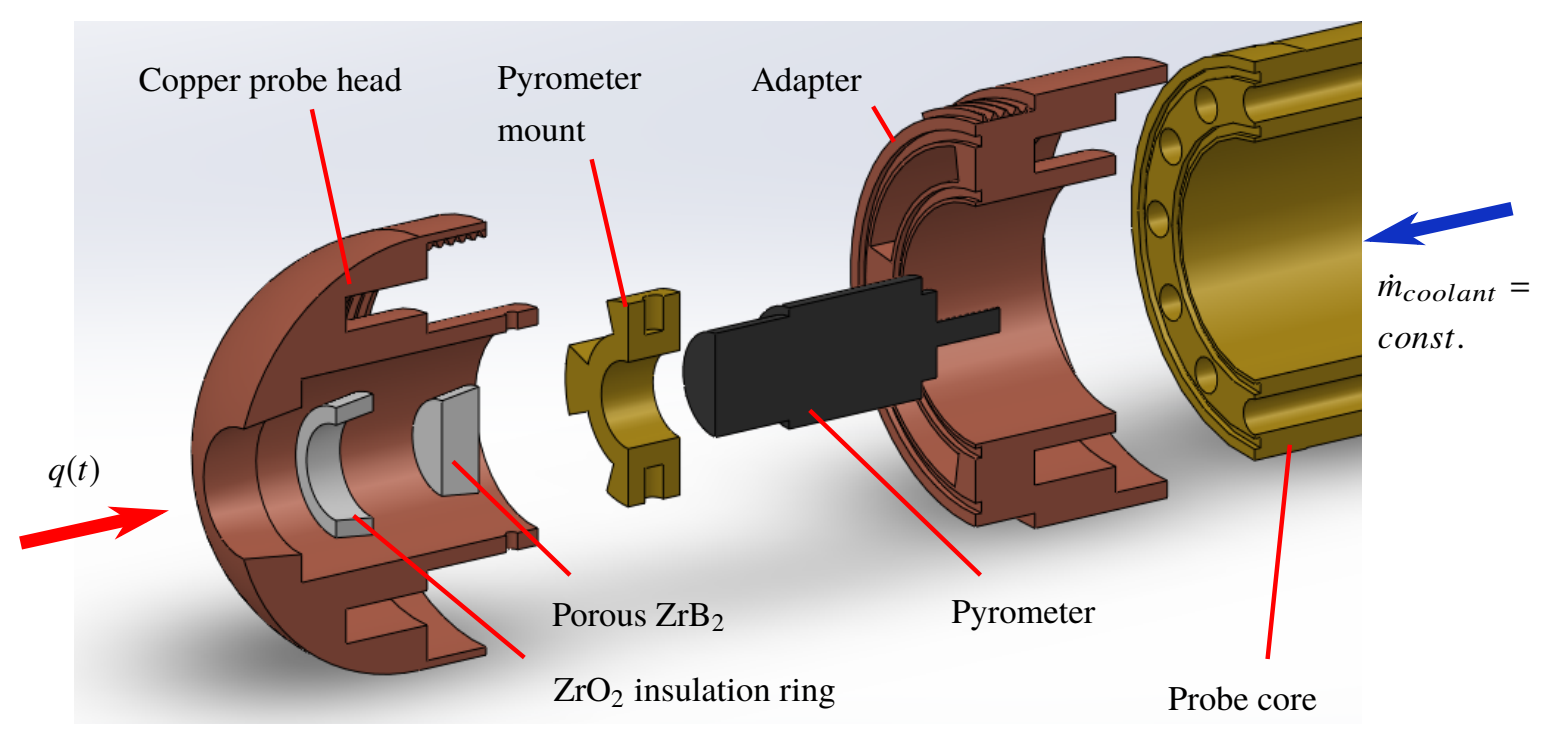

Fig. 3 Concept drawing of the NISIp probe for measurements in the IRS plasma wind tunnels.

\section{B. Setup for Plasma Wind Tunnel Tests}

The probe described in subsection IV.A was designed for measurements in the plasma wind tunnels at IRS. In these facilities, a stagnation point heat flux of up to $17.5 \mathrm{MW} / \mathrm{m}^{2}$ can be achieved [15]. However, the tests, whose results are presented in this paper, took place in the PWK4, which is depicted in Fig. 4a The condition which was investigated in this paper was characterized with a hemispherical $(50 \mathrm{~mm}$ diameter) calorimetric heat flux probe with a fully catalytic copper head. This probe was used because its head has the same shape as the sensor heads investigated within this work. Furthermore it can be seen as a reference heat flux probe [16, 17]. A stagnation point heat flux of $2 \mathrm{MW} / \mathrm{m}^{2}$ was measured, which equals the uncooled case for the investigations in this paper. As mentioned in the introduction, the coolant will form a layer of relatively cool gas between the sample's surface and the plasma [4]. This effect is expected to reduce the temperature gradient between the surface and the ambient gas, which results in a lower heat flux into the probe.

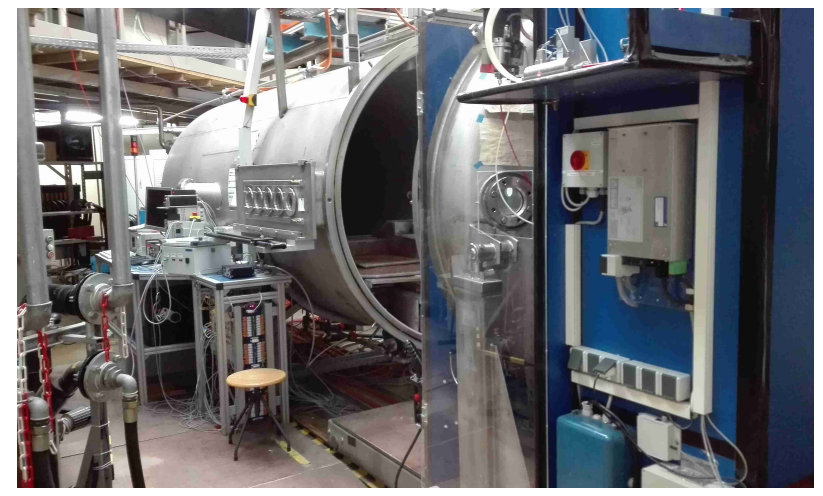

(a)

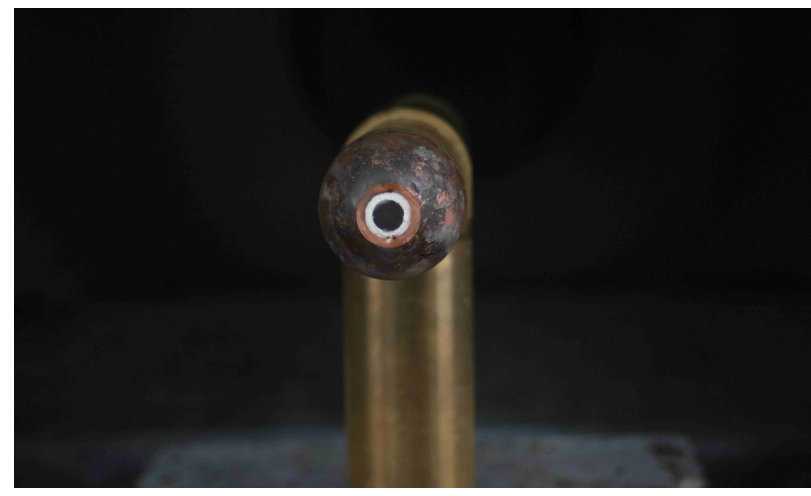

(b)

Fig. 4 Plasma wind tunnel (PWK4) at IRS (a) and assembled probe with sensor head P2 in the PWK4 (b).

Compared to the calibration setup, the sensor in the actual measurement is heated by the plasma flow. Other than that, the schematic of the setup for the plasma wind tunnel tests equals that of the calibration setup. The probe is mounted on a movable mount. During testing, the probe was moved at a constant speed through the plasma jet, where the position was recorded by the same oscilloscope the pressure data was recorded with, which allows for synchronisation of the two signals. This ensures a transient measurement with respect to an initial condition, where the probe is located besides the 
plasma jet where no heat flux is applied to the surface. This procedure is expected to result in a measured heat flux profile shaped similar to a Gaussian function, since the radial profile of the heat flux in the plasma flow follows this distribution [18].

During the plasma wind tunnel test, a sufficiently low sample surface temperature of below $250^{\circ} \mathrm{C}$ which was monitored using an external thermographic camera (FLIR A6751sc SLS). This is essential in order to inhibit oxidation of the $\mathrm{ZrB}_{2}$ sample, which would annul the validity of the calibration as the porous sample acting as the sensor would change. For this purpose, the movement speed was adapted between tests. For the most tests with Helium, a movement speed of $1000 \mathrm{~mm} / \mathrm{min}$ was set (exception is mass flow rate of $0.5 \mathrm{mg} / \mathrm{s}: 2000 \mathrm{~mm} / \mathrm{min}$ ). For Nitrogen a nominal movement speed of $500 \mathrm{~mm} / \mathrm{min}$ was chosen with the exception of the tests with a flow rate of $60 \mathrm{mg} / \mathrm{s}$, where it was set to $1000 \mathrm{~mm} / \mathrm{min}$. These deviations of test durations introduce uncertainties for the determined heat flux profiles and the comparison amongst them.

\section{Results}

\section{A. Calibration}

A calibration procedure as described in section III was conducted for both sensor heads subject to this paper. The coolant for the tests with sensor head P5 was Nitrogen, P2 was calibrated and tested with Helium. The mass flow rates for nitrogen were in the range of 10 to $60 \mathrm{mg} / \mathrm{s}$ and 0.5 to $2 \mathrm{mg} / \mathrm{s}$ for Helium. The respective flow rate was held constant, while a series of laser pulses was applied to the sample's surface. The measured pressure profile as well as the laser signal was digitally filtered using an FIR filter scheme in order to reduce the measurement noise. The NISIp parameters in Eq. (1) were found by fitting the simulated pressure profile to the one recorded during calibration. Using a numerical implementation of a Dirac impulse $\left(1 \mathrm{~W} / \mathrm{m}^{2}\right.$ for the length of one time step $\left.(0.2 \mathrm{~s})\right)$, the pressure impulse response was calculated with the found parameter set. The resulting pressure impulse responses are depicted in Fig. 5 for sensor head P5, which was cooled with Nitrogen (a), and for sensor head P2 cooled by Helium (b). As can be seen in both plots, the maximum amplitude of the pressure impulse responses are higher for increasing coolant mass flow rates. Despite not being explicitly depicted, the maximum amplitude is reached sooner for higher flow rates in both tests. A similar behaviour was already observed and investigated in a previous publication for two test setups hosting different porous materials [8].

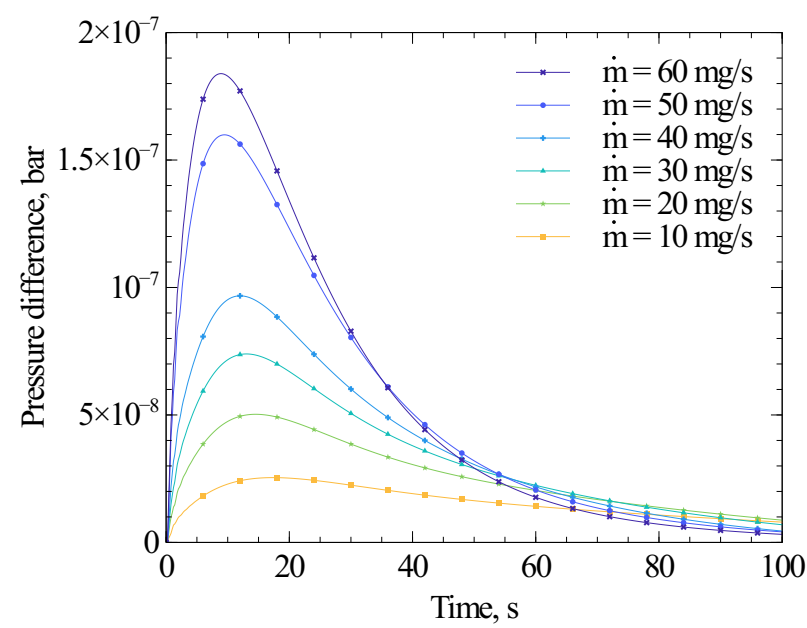

(a)

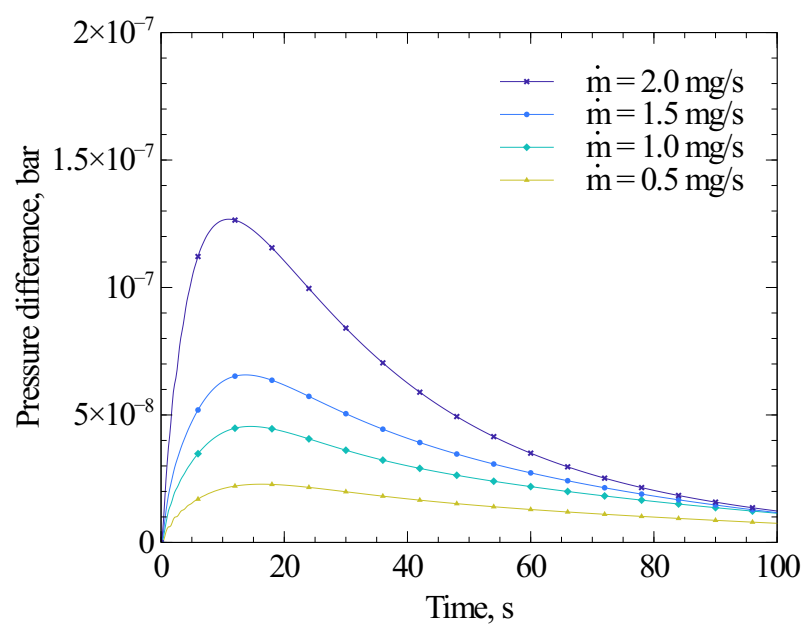

(b)

Fig. 5 Pressure impulse responses for varying coolant gas mas flows for sensor head P5 and Nitrogen (a) and P2 and Helium (b). 


\section{B. PWK measurement}

The impulse responses depicted in Fig. 5 were then used for the inversion of the surface heat flux in the PWK4 tests. Here, the plenum pressure and the probe's position was recorded while the probe moved through the plasma jet. It is assumed, that the heat flux into the surface equals 0 while the probe is located outside the plasma jet. Also in this case for noise reduction, the measured pressure profile was digitally filtered using an FIR filter scheme. Fig. 6 shows the determined surface heat fluxes for different coolant mass flow rates for P5 (a) and P2 (b). For each flow rate, the probe was moved back and forth along the y-axis (normal to the flow direction) through the jet. In each plot, the blue to green curves represent the tests in which the probe moved from a positive y-location towards the negative y-direction. The red to yellow curves represent the heat flux calculated from pressure profiles obtained for a movement into positive $y$-direction. One can observe, that the shape of the heat flux profile depends on the direction the probe moved towards. Especially in the measurement with sensor head P5 and for higher coolant mass flow rates, a rather high deviation of the reconstructed heat flux peak from the centre of the plasma jet can be seen. Also, the profile of the reconstructed heat flux falls off slower after the probe passed through the jet than it rises when moving into it. A similar even though less distinct asymmetry in the reconstructed heat flux profiles was already observed in past publications, where the NISI method based on temperature measurements was applied [19]. The reason for this is yet unclear.

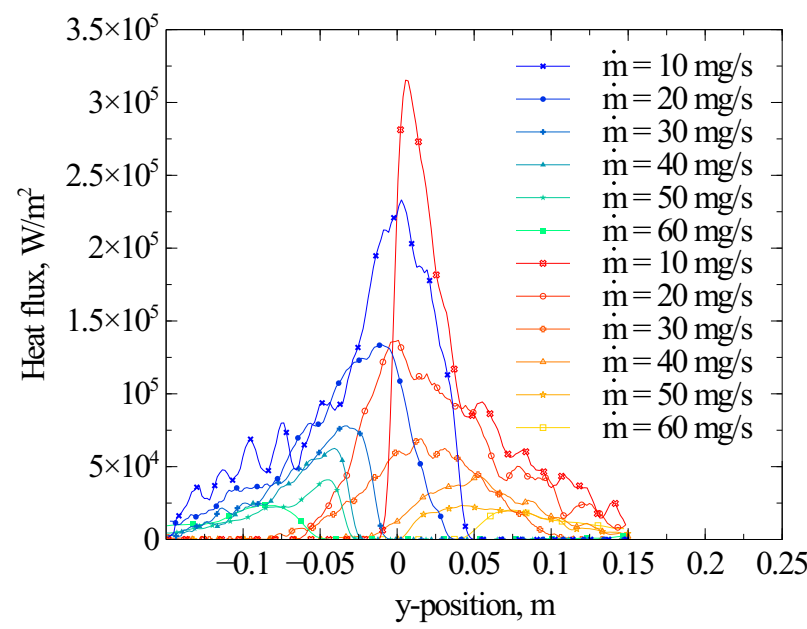

(a)

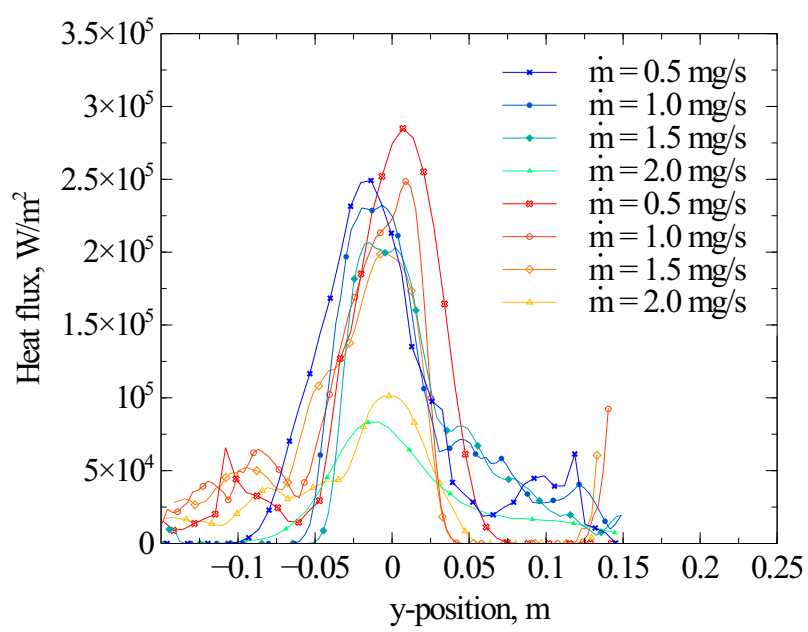

(b)

Fig. 6 For varying coolant gas mas flows, the surface heat flux profiles over y-position (normal to flow direction, 0 equals centre of plasma jet) for sensor head P5 and Nitrogen (a) and P2 and Helium (b); blue to green curves: movement toward -y-direction; red to yellow curves: movement toward $+y$-direction.

As can be seen in Fig. 6 the peak heat flux increases with decreasing coolant mass flow rates in both plots. This confirms the presence of a cooling layer between porous sample and plasma as described above. This cooling layer can also be observed, when comparing the shock region right in front of the probe in Fig. 7 Here, sensor head P5, which was cooled by Nitrogen, is depicted while located in the centre axis of the plasma jet flowing from left to right. Fig.7a shows the case where Nitrogen is blown out of the porous sample forming a dark thus cool region in front of the porous sample. This dark spot is missing in Fig. $7 \mathrm{~b}$, where a significantly lower coolant mass flow rate was set.

The highest peak heat flux of both experiments (red line in Fig. 5a is approximately $0.32 \mathrm{MW} / \mathrm{m}^{2}$, which is merely $16 \%$ of the uncooled heat flux of $2 \mathrm{MW} / \mathrm{m}^{2}$. Note, that the reference heat flux was determined using a different probe with a fully catalytic copper surface. Besides the heat flux reduction by inducing a coolant into the boundary layer also the surface's catalytic properties has an influence of yet unknown extent. The confirmation of the determined peak heat flux values is subject to future investigations.

Comparing the mass flow rates and the resulting peak heat fluxes, it can be deduced that the effectiveness of the cooling with Helium is significantly higher than for Nitrogen. This is consistent with the results by Langener et al. [20].

A possible explanation for the rather distinct asymmetry is that the probe passed through the jet too quickly for the given response time of the system rendering the heat flux inversion difficult. Besides the obvious solution of reducing the movement speed when passing through the jet, a smaller plenum volume appears essential. This would crucially quicken the system's response time for more precise measurements, as discussed in [8]. 


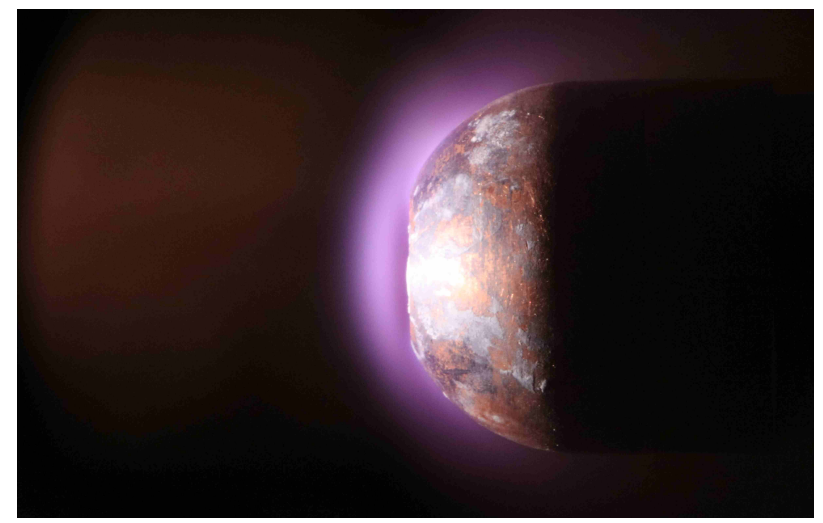

(a)

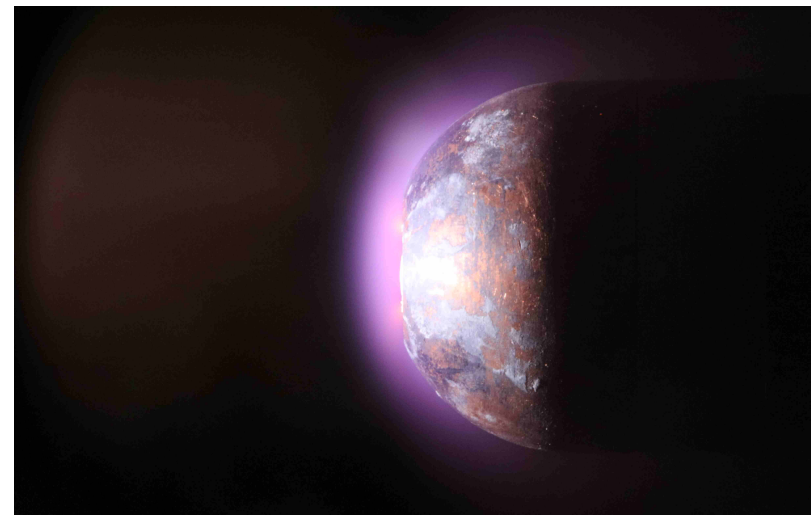

(b)

Fig. 7 Sensor head P5 transpiration cooled by Nitrogen for a high (a) and a low coolant flow rate (b).

Fig. 8 shows the peak values of the reconstructed heat fluxes with respect to the uncooled heat flux over the normalized mass flow rate. For both used coolants, Nitrogen and Helium, and at each mass flow rate, the peaks of the heat flux profiles for both movement directions (toward $+\mathrm{y}$ or $-\mathrm{y}$ direction) and their mean value is shown. Assuming a fully catalytic surface, the uncooled heat flux is $2 \mathrm{MW} / \mathrm{m}^{2}$.

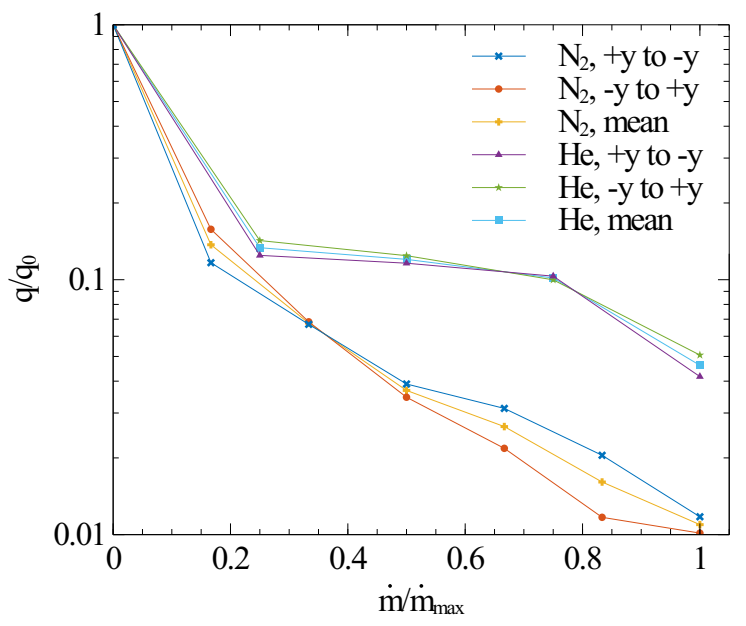

Fig. 8 Normalized surface heat fluxes over normalized mass flow rates for both respective measurements with Nitrogen and Helium and the respective mean value. $\dot{m}_{\max }$ is $2 \mathrm{mg} / \mathrm{s}$ for Helium and $60 \mathrm{mg} / \mathrm{s}$ for Nitrogen.

\section{Summary}

A review of the NISIp methodology and the respective setups for calibration and plasma wind tunnel test is described in this paper. The results of a calibration based on the NISIp method of two sensor heads using two coolants Nitrogen and Helium is laid out. Experiments in the plasma wind tunnels at IRS with the calibrated sensor system have been conducted successfully. The heat flux profile at varying coolant gas mass flows were successfully determined confirming the increased effectiveness of Helium as a coolant. Even for low mass flow rates a heat flux of $84 \%$ with respect to the uncooled case was found. The confirmation of the determined peak heat flux values is subject to future investigations. It was found that for future measurements a smaller plenum volume is to be realized and if possible a slower movement through the plasma jet. 


\section{Acknowledgments}

This work is partly funded through the ESA NPI Program under contract No. 4000121220/17/NL/MH. The authors thank the members of the High Enthalpy Flow Diagnostics Group, namely Martin Eberhart, Fabian Zander (now: University of Southern Queensland), Arne Meindl, David Leiser, Igor Hörner and Felix Grigat for their effort preparing and conducting the test campaign. The authors thank Laura Larrimbe, Daniel Glymond and Luc Vandeperre from Imperial College London for providing the material samples and the respective thermophysical properties.

\section{References}

[1] Gupta, R. N., "Aerothermodynamic Analysis of Stardust Sample Return Capsule with Coupled Radiation and Ablation," Journal of Spacecraft and Rockets, Vol. 37, No. 4, 2000, pp. 507-514.

[2] Preclik, D., Wiedmann, D., Oechslein, W., and Kretschmer, J., "Cryogenic rocket calorimeter chamber experiments and heat transfer simulations," 34th AIAA/ASME/SAE/ASEE Joint Propulsion Conference and Exhibit, 1998, p. 3440.

[3] Arnold, R., Experimentelle Untersuchungen zur Filmkühlung in Raketenbrennkammern, Cuvillier, 2008.

[4] Boehrk, H., Piol, O., and Kuhn, M., "Heat Balance of a Transpiration-Cooled Heat Shield," Journal of Thermophysics and Heat Transfer, Vol. 24, No. 3, 2010, pp. 581-588. doi:10.2514/1.47172, URL https://doi . org/10.2514/1.47172

[5] Battaglia, J.-L., Cois, O., Puigsegur, L., and Oustaloup, A., "Solving an Inverse Heat Conduction Problem Using a Non-integer Identified Model," International Journal of Heat and Mass Transfer, Vol. 44, 2001, pp. 2671-2680.

[6] Loehle, S., Battaglia, J.-L., Jullien, P., van Ootegem, B., Couzi, J., and Lasserre, J.-P., "Improvement of High Heat Flux Measurements using a null-point Calorimeter," Journal of Spacecrafts and Rockets, Vol. 45, No. 1, 2007, pp. 76-81.

[7] Loehle, S., Schweikert, S., and von Wolfersdorf, J., "Method for Heat Flux Determination of a Transpiration Cooled Wall from Pressure Data," Journal of Thermophysics and Heat Transfer, Vol. 30, No. 3, 2016, pp. 567-572. doi:https: //doi.org/10.2514/1.T4815.

[8] Hufgard, F., Loehle, S., Hermann, T., Schweikert, S., McGilvray, M., von Wolfersdorf, J., Steelant, J., and Fasoulas, S., “Analysis of Porous Materials for Transpiration Cooled Heat Flux Sensor Development," International Conference on High-Speed Vehicle Science Technology, CEAS, 2018.

[9] Schweikert, S., Loehle, S., Selzer, M., Boehrk, H., and von Wolfersdorf, J., "Surface Heat Flux Determination of Transpiration Cooled C/C by the Application of Non-integer System Identification," 8th European Workshop on Thermal Protection and Hot Structures, ESA, 2016.

[10] Gardarein, J.-L., Battaglia, J.-L., and Loehle, S., "Heat flux sensor calibration using noninteger system identification: Theory, experiment, and error analysis," Review of Scientific Instruments, Vol. 80, No. 025103, 2009. doi:10.1063/1.3079328.

[11] Loehle, S., "Derivation of the Non-integer System Identification Method for the Adiabatic Boundary Condition using Laplace Transform," International Journal of Heat and Mass Transfer, Vol. 115, 2017, pp. 1144-1149. doi:10.1016/j.ijheatmasstransfer. 2017.08.007.

[12] Ljung, L., System Identification: Theory for the user, Prentice Hall, 1987.

[13] van Cittert, P. H., "Zum Einfluss der Spaltbreite auf die Intensitätsverteilung in Spektrallinien,” Zeitschrift für Physik, Vol. 65, No. 547,1931

[14] Ewnez Rocher, M., Hermann, T., McGilvray, M., Ifti, H. S., Hufgard, F., Eberhart, M., Meindl, A., Loehle, S., and Zander, F., "Testing a Transpiration Cooled Zirconium-Di-Boride sample in the Plasma Tunnel at IRS," 2019 AIAA SciTech Forum, American Institute of Aeronautics and Astronautics, 2019.

[15] Loehle, S., Fasoulas, S., Herdrich, G., Hermann, T., Massuti-Ballester, B., Meindl, A., Pagan, A. S., and Zander, F., “The Plasma Wind Tunnels at the Institute of Space Systems: Current Status and Challenges," 46th Aerodynamic Measurement Technology and Ground Testing Conference, AIAA, 2016. doi:10.2514/6.2016-3201.

[16] Loehle, S., Nawaz, A., Herdrich, G., and Fasoulas, S., "Comparison of Heat Flux Gages for High Enthalpy Flows - NASA Ames and IRS," 46th Aerodynamic Measurement Technology and Ground Testing Conference, AIAA, 2016.

[17] Loehle, S., Steinbeck, A., and Fasoulas, S., "Local Mass-Specific Enthalpy Measurements with a New Mass Injection Probe," Jornal of Thermophysics and Heat Transfer, Vol. 30, No. 2, 2016, pp. 301-307. doi:10.2514/1.t4709. 
[18] Lein, S., "Entwicklung eines auf Emissionsspektroskopie basierenden Sensorsystems zum Einsatz auf Wiedereintrittsplattformen," 2016.

[19] Nawaz, A., Loehle, S., Herdrich, G., and Martinez, E. R., "Comparison of Calorimetric Sensors - Nasa Ames and IRS," 44th AIAA Thermophysics Conference, AIAA, 2013.

[20] Langener, T., von Wolfersdorf, J., and Steelant, J., "Experimental Investigations on Transpiration Cooling for Scramjet Applications Using Different Coolants,” AIAA Journal, Vol. 49, No. 7, 2011, pp. 1409-1419. doi:10.2514/1.j050698, URL https://doi.org/10.2514/1.j050698 